\title{
(5)
}

\section{PARÂMETROS PARA A ATUAÇÃO DE ASSISTENTES SOCIAIS NA POLÍTICA DE SAÚDE: O SIGNIFICADO NO EXERCÍCIO PROFISSIONAL}

Parameters for the practice of social assistants in health policy: the meaning in the work exercise

\author{
Débora Cristina da Silva* \\ Tânia Regina Krüger* * \\ (c) () (2)
}

\section{RESUMO}

Este artigo tem como objetivo identificar o significado que os Parâmetros para a Atuação de Assistentes Sociais na Política de Saúde representam para o exercício profissional no âmbito hospitalar. Este documento de subsídio para atuação do serviço social na saúde completará uma década, em que se observa a necessidade de refletir sobre o seu significado e em que medida representa adensamento teóricometodológico, político e operativo para o exercício profissional. Metodologicamente, a pesquisa se caracterizou como exploratória e qualitativa, através da realização de grupos focais com assistentes sociais que atuam em dois hospitais da grande Florianópolis. Os resultados apontam que há um superficial conhecimento do referido documento, com ênfase no eixo de atendimento direto aos usuários e o reconhecimento de práticas vinculadas essencialmente às demandas socioassistenciais e emergenciais. Em grande medida, ficou ausente nos grupos focais a referência política do documento em relação aos fundamentos do projeto ético político do serviço social e do Sistema Único de Saúde.

PALAVRAS-CHAVE: Saúde. Serviço social. Exercício profissional.

\footnotetext{
Assistente Social. Especialista com titulação em Residência Integrada Multiprofissional em Saúde/Ênfase em Alta Complexidade HU/UFSC. Mestranda em Serviço Social do programa de pósgraduação UFSC. Assistente Social da Unidade de Pronto Atendimento Forquilhinha. (UPA, São José (SC), Brasil). Rua Vereador Arthur Manoel Mariano, n. 1439, Forquilhinha, São José (SC), CEP.: 88106-501. E-mail: <dehboracs89@gmail.com>. ORC ID: <https://orcid.org/0000-0001-8468-3432>.

** Assistente Social. Pós-doutoranda no Centro de Estudos Sociais (CES), Universidade de Coimbra. (UC, Coimbra, Portugal). Professora Pesquisadora (PQ2) do CNPq. Docente do Departamento de Serviço Social da Universidade Federal de Santa Catarina. (UFSC, Florianópolis, Brasil). Campus Reitor João David Ferreira Lima, s/n, Trindade, Florianópolis (SC), CEP.: 88040-900. E-mail: <tania.kruger@ufsc.br>. ORC ID: <https://orcid.org/0000-0002-7122-6088>.
} 


\section{ABSTRACT}

The aims of this article is identify the meaning that the Parameters for the Acting of Social Workers in the Health Policy represent for the professional exercise in the hospital scope. This document of subsidy for Social Work in the health, will complete a decade and it is observed the necessity or reflect about its meaning and to what extent it represents a theoretical-methodological, political and operational density for the professional exercise. Methodologically, there search was characterized as exploratory and qualitative, through the realization of focus groups with social workers who work in two hospitals in the greater Florianópolis. The results indicate that there is a superficial knowledge of the mentioned document, with emphasis on the axis of direct service to users and the recognition of practices essentially linked to socio assistential and emergency demands. The political reference of the document to the foundations of the ethical political project of the social service and the Unified Health System was largely absent from the focus groups.

\section{KEYWORDS}

Health. Social work. Professional exercise.

Submetido em: 18/4/2018.

Aceito em: 6/6/2018.

\section{INTRODUÇÃO}

Sem perder de vista as expressões da questão social na sociedade capitalista e o espaço privilegiado do exercício profissional do assistente social nas políticas sociais, esta pesquisa objetiva tratar da particularidade do exercício profissional na política de saúde. O Serviço Social brasileiro integra o rol das profissões em saúde, tanto no plano legal como através da legitimação social, a partir do conceito ampliado de saúde. Os assistentes sociais como profissionais de saúde são reconhecidos na Resolução $n^{\circ} 218$, de 6 de março de 1997, do Conselho Nacional de Saúde e na Resolução do Conselho Federal de Serviço Social (CFESS) n 383/1999.

Em termos de princípios, o projeto ético-político ${ }^{1}$ do serviço social posiciona-se a favor da ampliação da cidadania, aprofundamento da democracia, equidade e justiça social, indo ao encontro dos fundamentos do Sistema Único de Saúde (SUS). Igualmente, o assistente social, trabalhador da saúde, reconhece um conceito ampliado de saúde 2 que ultrapassa a concepção saúde/doença, atuando nos níveis de promoção e

\footnotetext{
${ }^{1}$ Como principais fundamentos da estruturação do Projeto Ético-Político da década de 1990, destacamse: o Código de Ética de 1993, pelo CFESS e a Lei de Regulamentação da Profissão n 8.662 de 1993. Além destes, em 1996, foram lançadas Diretrizes Curriculares, pela ABEPSS, em paralelo à ampliação das pesquisas nos Programas de Pós-Graduação e de publicações que vêm sustentando teórica, metodológica, técnica e politicamente o Projeto Ético-Político.

${ }^{2}$ Saúde não é simplesmente não estar doente, posto que o conceito vai além: é um bem-estar social, é o direito ao trabalho, a um salário condigno; é o direito a ter água, à vestimenta, à educação e até a informação sobre como se pode dominar o mundo e transformá-lo. É ter direito a um meio ambiente que não seja agressivo, mas que, pelo contrário, permita a existência de uma vida digna e decente; a um sistema político que respeite a livre opinião, a livre possibilidade de organização e de autodeterminação de um povo. É não estar todo tempo submetido ao medo da violência, tanto daquela violência resultante da miséria, que é o roubo, o ataque, como a violência de um governo contra o seu próprio povo para que sejam mantidos os interesses que não sejam os do povo (AROUCA, 1987, p. 36).
} 


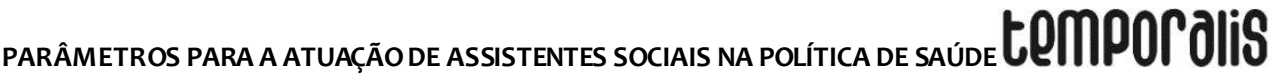

prevenção da saúde. De acordo com Bravo (2013), “[...] a saúde passa a ser considerada um meio e um fim para o desenvolvimento e o bem-estar" (BRAVO, 2013, p. 67). Com estes referenciais, o profissional passa a ter maior reconhecimento social e demanda na área da saúde, em meio às equipes multiprofissionais. Além disso, entende a questão social como objeto da intervenção profissional, que se manifesta por um conjunto muito variado de expressões, tornando fundamental o exercício profissional se pautar nas diretrizes do SUS: a integralidade, a universalidade do acesso, a intersetorialidade, a participação deliberativa, a interdisciplinaridade, dentre outras (CONSELHO FEDERAL DE SERVIÇO SOCIAL, 2010).

Desta forma, este artigo $^{3}$ é resultado do Trabalho de Conclusão da Residência Integrada Multiprofissional em Saúde pela Universidade Federal de Santa Catarina e tem como objetivo identificar o significado 4 que os Parâmetros para a Atuação de Assistentes Sociais na Política de Saúde 5 (CONSELHO FEDERAL DE SERVIÇO SOCIAL, 2010) representam para o exercício profissional.

Para atingir o propósito deste artigo, cabe evidenciar as questões particulares do processo metodológico. Para a execução da pesquisa, foi necessário realizar revisão da literatura sobre a política de saúde brasileira, do serviço social na saúde e sobre os fundamentos do documento Parâmetros para a Atuação de Assistentes Sociais na Saúde, suas bases teóricas, legais e operacionais.

Neste artigo, utilizou-se a análise crítica com vistas a possibilitar a aproximação da realidade social, posto que ela contempla elementos de historicidade, contradição e totalidade. O significado que os Parâmetros para a Atuação de Assistentes Sociais na Política de Saúde têm para o exercício profissional coloca o desafio de realizar reflexões considerando estes três elementos da perspectiva crítico-dialética. A pesquisa empírica caracteriza-se como qualitativa e de caráter exploratório e tem a necessidade de refletir sobre os significados e respostas para a complexidade da prática.

Definiu-se, como procedimento operacional, a utilização de grupos focais para coletar informações pertinentes à pesquisa. De acordo com Trad (2009), os grupos focais têm

\footnotetext{
${ }^{3}$ Este artigo é um recorte do projeto da pesquisa "Saúde e Serviço Social: planejamento, gestão, participação e exercício profissional"; a ser realizado no período 2015-2019, registrado no sistema Notes UFSC com o seguinte protocolo: 2015.0056, vinculado ao Núcleo de Estudos em Serviço Social e Organização Popular (NESSOP) do Departamento de Serviço Social da Universidade Federal de Santa Catarina (UFSC). O projeto é conduzido pela Professora Dra. Tânia Regina Krüger, docente da graduação e da pós-graduação do Serviço Social da UFSC e orientadora do presente artigo.

${ }^{4}$ De acordo com o Dicionário de Filosofia, a palavra significado, frequentemente citada neste artigo, é entendida como "Possibilidade de um signo referir-se a seu objeto. Para os estoicos, o Significado se divide em três elementos que se inter-relacionam: o Significado, aquilo que significa e aquilo que é. Para a Filosofia Clínica, Significado diz respeito à maneira e à interpretação que a pessoa empresta aos conceitos e aos termos que habitam sua malha intelectiva. Nesse sentido, uma interpretação é um parecer, não necessariamente uma sentença" (SÓ FILOSOFIA, C2008-2018, não paginado).

${ }^{5} \mathrm{O}$ referido documento foi elaborado de forma coletiva pelo Conselho Federal de Serviço Social (CFESS), entre os anos de 2008 e 2009 e publicado em 2010, tendo por objetivo subsidiar a intervenção dos profissionais do Serviço Social na área da saúde.
} 
como “[...] principal objetivo reunir informações detalhadas sobre um tópico específico (sugerido por um pesquisador, coordenador ou moderador do grupo) a partir de um grupo de participantes selecionados" (TRAD, 2009, p. 780). Desta forma, este instrumento diferencia-se da entrevista individual, pois se fundamenta na interação do grupo para obter respostas à pesquisa. Sendo assim, Gondim (2003, p. 151) complementa dizendo que "[...] a unidade de análise do grupo focal, no entanto, é o próprio grupo. Se uma opinião é esboçada, mesmo não sendo compartilhada por todos, para efeito de análise e interpretação dos resultados, ela é referida como grupo" (GONDIM, 2003, p. 151).

O universo da pesquisa empírica foi composto por dezenove assistentes sociais (residentes e trabalhadores) do Hospital Universitário vinculado à Universidade Federal de Santa Catarina e assistentes sociais de outro hospital geral público da grande Florianópolis. Foi utilizado um roteiro semiestruturado para conduzir o processo de coleta de dados junto aos grupos focais.

Em relação aos sujeitos participantes da pesquisa, e em respeito ao Código de Ética Profissional do Serviço Social e ao Comitê de Ética em Pesquisa com Seres Humanos, foi mantida em sigilo a identificação dos profissionais que participaram da pesquisa ${ }^{6}$.

O presente artigo se organiza em três momentos: $1^{\circ}$ ) resgate histórico e teórico do Serviço Social na saúde; $2^{\circ}$ ) contextualização do documento Parâmetros para a Atuação de Assistentes Sociais na Política de Saúde, considerando sua construção e bases teóricas, legais e operacionais; $3^{\circ}$ ) análise dos dados da pesquisa com ênfase na problematização dos referenciais utilizados no exercício profissional do Assistente Social no âmbito hospitalar e sua relação com os Parâmetros para a Atuação de Assistentes Sociais na Política de Saúde.

\section{O SERVIÇO SOCIAL NA SAÚDE: TRAJETÓRIA E TENDÊNCIAS DOS ANOS 2000}

Para tratar do objeto desse artigo, primeiramente é necessário destacar algumas considerações sobre a trajetória e tendências do Serviço Social na Saúde no decorrer dos anos 2000. Dessa forma, para melhor entendimento, será delineada uma breve síntese sobre o projeto ético-político profissional e a relação com o projeto da Reforma Sanitária. De acordo com Machado (2008):

\footnotetext{
Nasce um novo projeto do Serviço Social, por meio da contestação ao conservadorismo profissional, advindo das décadas de 1970 e de 1980, período este que marca um momento importante no desenvolvimento da profissão no Brasil, acentuado principalmente pelo enfrentamento e pela denúncia deste conservadorismo (MACHADO, 2008, p. 23).
}

Uma década após este período, o processo de recusa e crítica do conservadorismo dá origem a um novo projeto profissional. Este projeto trata de uma construção coletiva,

\footnotetext{
6 Os profissionais da pesquisa serão identificados pelos números (1, 2, 3 e sucessivamente até 19). Ressalta-se que a pesquisa foi submetida ao Comitê de Ética em Pesquisa da UFSC, sob aprovação com parecer número 2.079.144, na data de 24 de maio de 2017 e cumpriu os requisitos preconizados na Resolução 466/2012, no que se refere às normas e diretrizes de pesquisas que envolvem seres humanos.
}

Temporalis, Brasília (DF), ano 18, n. 35, jan./jun. 2018. 


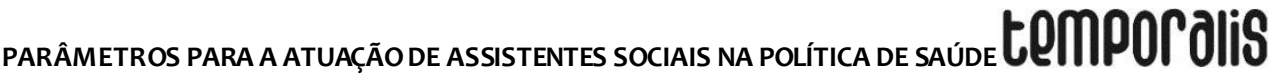

que teve seu início a partir do Movimento de Reconceitualização, na intenção de romper com a herança conservadora. Por ser um projeto de natureza histórica, está sujeito a transformações, atualizações, avanços e regressividade em seus fundamentos.

A literatura das políticas sociais em geral reconhece que a saúde foi uma das áreas em que os avanços constitucionais foram mais significativos. Em 1988, a saúde, após lutas do Movimento de Reforma Sanitária, passa a ser considerada direito social e dever do Estado. A Constituição reconheceu como dever do Estado garantir a saúde da população por meio do Sistema Único de Saúde (SUS). Em 1990, o SUS foi regulamentado pelas Leis Orgânicas da Saúde (LOS) 8.080/1990 e 8.142/1990. A Reforma Sanitária é um movimento social que tem como projeto a defesa da saúde pública universal. Nessa concepção que o SUS foi incorporado na Constituição Federal. Com o SUS, em tese, há uma ruptura do entendimento de política de saúde médicocurativa e há ênfase na concepção da universalidade do acesso e na integralidade da assistência. Além de trazer um novo conceito do que é saúde, reconheceu-se a determinação social da saúde e da doença por meio da alimentação, moradia, lazer, emprego, trabalho, educação, segurança, meio ambiente, acesso à terra, etc.

De acordo com Krüger (2016), “[...] o conceito ampliado de saúde e o reconhecimento da determinação social da saúde representam um ganho civilizacional para sociedade na medida em que considera que a saúde da sua população reflete a organização social e econômica do País" (KRÜGER, 2016, p. 1). Reconhecimento de extrema importância para um país com nível elevado de desigualdade social, identificando, através do projeto da Reforma Sanitária, as condições de vida como determinação da saúde e da doença. E é a partir da mesma época, a partir dos anos 2000, que o SUS tem suas bases legais, materiais e financeiras mais disputadas no país.

Em meio aos embates para a implementação do SUS, no âmbito da saúde e, mais fortemente, a partir dos anos 2000, evidencia-se uma gradativa produção do serviço social, bem como a participação nas discussões de saúde coletiva e a introdução de profissionais nos órgãos representativos, técnico-políticos e em espaços de controle social. Conforme CFESS (2010):

A nova configuração da política de saúde vai impactar o trabalho do assistente social em diversas dimensões: nas condições de trabalho, na formação profissional, nas influências teóricas, na ampliação da demanda e na relação com os demais profissionais e movimentos sociais (CONSELHO FEDERAL DE SERVIÇO SOCIAL, 2010, p. 23).

A atuação e as áreas de intervenções profissionais do Serviço Social no campo da saúde mudaram ao longo da história e, particularmente, a partir da definição do conceito de saúde. Dessa forma, a partir da regulamentação do SUS, com o conceito ampliado de saúde, com seus princípios e competências, o Serviço Social aumentou significativamente seu espaço de trabalho e alargou suas reflexões nessa área. 
Os 30 anos de implementação do SUS não foram nada lineares. As disputas foram acirradas pelo modelo de atenção e de gestão e, sobretudo, por seu financiamento. Assim, identificam-se, no âmbito governamental, nas universidades, nas entidades científicas da área da saúde, nos movimentos sociais, nos fóruns de trabalhadores da área, nos Conselhos de Saúde das três esferas de governo, nas associações de prestadores privados e filantrópicos, nos instrumentos de gestão e nos Relatórios de Conferências três perspectivas em disputa: a da Reforma Sanitária, a privatista e a flexibilizadora-transformista. Tais propostas não são retilíneas e nem possuem fronteira delimitada (BRAVO; PELAEZ; PINHEIRO, 2018).

O projeto da Reforma Sanitária que construiu o SUS pauta-se na radicalidade democrática, sendo que, por meio de seus princípios doutrinários e organizacionais, defende o direito universal de acesso, gratuidade, integralidade do atendimento, gestão pública estatal, participação popular deliberativa, plano de cargos, carreira e salários único para trabalhadores do SUS e recursos que devem ser investidos em serviço público. Nos governos dos anos de 1990 até meados da primeira década do ano 2000, fortaleceu-se o projeto privatista por meio da focalização e do desfinanciamento. O projeto privatista ganhou um novo fôlego a partir de $2016 \mathrm{com}$ as políticas do governo Michel Temer, com iniciativas que alteram o escopo e abrangência do SUS, tais como aprovação da Emenda Constitucional 241/20167, o chamado Novo Regime Fiscal; a proposta, em tramitação, de criação dos Planos de Saúde Acessíveis (planos privados populares); liberação do capital estrangeiro na saúde, por meio da Medida Provisória 656/2014 e posterior Lei 13.097/2015, aprovada no Congresso Nacional; revisão da Política Nacional de Atenção Básica (PNAB) e alteração das diretrizes da Política Nacional de Saúde Mental (PNSM). A proposta flexibilizadora do SUS emerge como um novo projeto do SUS possível. "O projeto do SUS possível é defendido pelas lideranças que diante dos limites da política econômica defendem a flexibilização da reforma sanitária, mas nomeiam esse processo como reatualização, modernização ou mesmo como continuidade desta" (SOARES, 2010, p. 53). A conjuntura regressiva a partir de 2016 fez os sujeitos dessa proposta em parte se aliarem aos sujeitos do projeto original e democrático-popular da Reforma Sanitária.

Particularmente no âmbito dos três projetos em disputa no SUS, Krüger (2016), avalia que "[...] as tendências reformistas, que defendiam um mix público/privado na gestão do SUS, voltam-se agora à defesa do SUS meio sem seus fundamentos, tendo em vista a total predominância da lógica do mercado" (KRÜGER, 2016, p. 2). Mas o cenário nos aponta para a contínua hegemonia do projeto privatista da saúde, aniquilamento do projeto da Reforma Sanitária e talvez certa sobrevida do projeto transformista, ficando um sistema público de saúde pobre para atender os pobres. Ou seja, um sistema público para a vigilância à saúde, para os procedimentos caros e de alta complexidade, para o interior do país em áreas que o setor privado não pode obter lucro e com as emergências.

\footnotetext{
7 As possíveis implicações do Novo Regime Fiscal para o financiamento do SUS e para a garantia do direito à saúde, contidas na proposta inicial que deu origem à Proposta de Emenda Constitucional $\mathrm{N}^{\circ}$ 241/2016 (PEC 241), foram analisadas em artigo de Vieira e Benevides (2016a) e em nota técnica do IPEA, publicada em 21/09/2016. (VIEIRA; BENEVIDES, 2016a; VIEIRA; BENEVIDES, 2016b).
} 


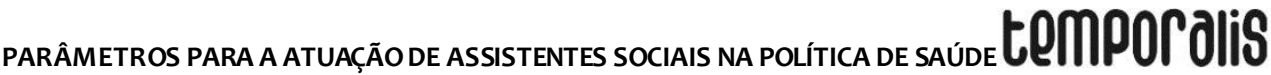

As disputas desses projetos tendo a hegemonia das forças neoliberais levaram a um conjunto de contrarreformas ${ }^{8}$ que vêm impondo sucateamento, descontinuidades, focalização, transformismos, desfinanciamento, privatização dos serviços do SUS em detrimento da integralidade e da universalidade, tendo entre suas consequências o aumento do trabalho precarizado dos profissionais, inúmeras restrições ao acesso dos usuários, a desresponsabilização do Estado e responsabilização da sociedade civil. A contrarreforma na política de saúde e do conjunto direitos sociais no Brasil ganhou um adensamento no país desde 2016. Em nome de resolver uma crise econômica, está forçando uma agenda ainda mais conservadora, aliada uma retórica de respeito à lei, à ordem e à segurança com práticas e políticas de adesão ao liberalismo econômico.

Para o Serviço Social, observa-se uma grande tendência a pautar o trabalho e a formação em disciplinas, em trabalhar com ênfase no cotidiano, em que se processa a vida nas demandas imediatas. Neste contexto, adquirem expressividade temas como a humanização, o cuidado / cuidador / autocuidado, a representação, a escuta qualificada, o vínculo, o acolhimento, a organização do Procedimento Operacional Padrão (POP) e dados epidemiológicos, apresentados sem muita interlocução com a política de saúde e com as determinações sociais da saúde. Considera-se que estes temas localizados respondem a demandas sociais e de saúde, dotadas de legitimidade. Mas ressaltamos que o processo técnico do exercício profissional e da formação não pode desconhecer a relação dessa qualificação com as questões fundamentais do SUS, a conjuntura de contrarreformas regressivas e do projeto ético-político do serviço social, e nem se submeter à flexibilização dos seus referenciais teórico-metodológicos com questionamentos difusos.

É nessa conjuntura de disputas do SUS que o Serviço Social evidencia maiores preocupações com sua prática. Como uma estratégia para afirmar as referências teórico-políticas do seu Projeto Profissional, o conjunto CFESS-CRESS deu início, em 2007, em eventos coletivos da categoria, ao debate de forma descentralizada sobre os Parâmetros para a Atuação do Assistente Social nas Políticas Sociais, com o objetivo de abordar a intervenção do assistente social em diversos espaços sócio-ocupacionais.

No próximo item, abordaremos os Parâmetros para a Atuação de Assistentes Sociais na Saúde (CONSELHO FEDERAL DE SERVIÇO SOCIAL, 2010), indicando algumas referências da sua construção, suas bases teóricas, metodológicas, legais e operacionais, enquanto um documento político e uma estratégia do Conjunto CFESS/CRESS de colocar em debate o exercício profissional.

\footnotetext{
8 Aqui adotamos o sentido de contrarreforma definido por Behring (2008), como o conjunto de reformas neoliberais no Estado brasileiro, que implicaram num profundo retrocesso social. A contrarreforma vivenciada no Brasil é um processo que historicamente aflige a classe trabalhadora. Com efeito, trata-se de “[...] uma contrarreforma conservadora e regressiva, diferente do que postulam os que a projetaram entre as paredes dos gabinetes tecnocráticos e inspirados nas orientações das agências multilaterais" (BEHRING, 2008, p. 171). A autora se "[...] recusa de caracterizar como reforma processos regressivos" (BEHRING, 2008, p. 171), por isso os qualifica como contrarreforma.
} 


\section{PARÂMETROS PARA A ATUAÇÃO DE ASSISTENTES SOCIAIS NA SAÚDE: CONSTRUÇÃO E BASES TEÓRICAS, LEGAIS E OPERACIONAIS}

O Conselho Federal de Serviço Social como autarquia pública tem a função de orientar, disciplinar, normatizar, fiscalizar e defender o exercício profissional do/a assistente social no Brasil, em conjunto com os Conselhos Regionais de Serviço Social (CRESS). Para além de suas atribuições, contidas na Lei 8.662/1993 (CONSELHO FEDERAL DE SERVIÇO SOCIAL, 1993), a entidade vem promovendo ações políticas para a construção de um projeto de sociedade democrático, anticapitalista e em defesa dos interesses da classe trabalhadora. Para este órgão, a defesa do exercício profissional do/a assistente social tem colocado inúmeros desafios. Por isso, desde meados da primeira década dos anos 2000, vem promovendo uma série de eventos e realizando publicações que se tornaram referências teóricas, políticas e técnicas na intervenção profissional em direção ao projeto profissional que a categoria vem construin do nos últimos 30 anos.

O projeto profissional do serviço social se desenvolveu e vem se sustentando na busca por uma fundamentação e consolidação teórica, metodológica, política e ética. Fruto de rigorosas pesquisas vinculadas, sobretudo nos Programas de Pós-Graduação da área, tem seu respaldo como área de conhecimento nas agências de fomento, nas densas publicações de livros e periódicos, no debate político que envolve os temas dos onze princípios do seu Código de Ética e na defesa intransigente dos direitos sociais. Mas estes significativos avanços não nos cegam às respostas prático-utilitaristas, intervenções idealizadas, espontaneístas, restritas às relações interpessoais, com predominância de atuação nos espaços assistencial e emergencial que caracterizam majoritariamente o exercício profissional.

Ciente desses desafios e em face da constatação da distância entre o acúmulo teóricopolítico referente aos serviços de ponta na relação com os usuários e empregadores/instituições, o CFESS promoveu uma série de eventos e publicações, no sentido de aproximar dois âmbitos da profissão: formação e trabalho profissional. Foram lançados quatro documentos pelo CFESS, representando subsídios de intervenção profissional na área da assistência social, da saúde, da educação e do espaço sociojurídico. Os dois primeiros documentos foram denominados pelo CFESS como parâmetros. Porém, depois de diversos questionamentos da base da categoria, o nome parâmetros foi substituído por subsídios. Os documentos da política de educação e do espaço sociojurídico, que foram os dois últimos lançados, são chamados de subsídios para atuação do assistente social (MACHADO, 2015).

Em nosso entendimento, estes documentos respondem a algumas análises amplamente divulgadas por Bravo e Matos (2007) e Vasconcelos (2006) sobre a distância entre o acúmulo teórico-político e metodológico e a materialização do exercício profissional. Vejamos: “Para se avançar hoje na profissão, se faz necessário recuperar as lacunas da década de 1980. A intervenção é uma prioridade, pois poucas alterações trouxeram os ventos da intenção e ruptura para o cotidiano dos serviços" (BRAVO; MATOS, 2007, p. 204).

Uma atividade mecânica, inconsciente, faz do assistente social um protagonista passivo no seu próprio espaço profissional [...]. Os assistentes 


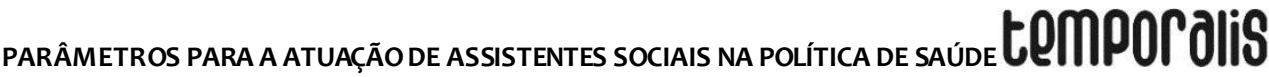

sociais são levados a um trabalho conservador que, direta ou indiretamente, consciente ou inconscientemente, reproduz e/ou reforça o status quo, sem conseguirem romper, na prática, com valores conservadores. Assim, mesmo apoiando o debate hegemônico do Serviço Social, a maioria desses profissionais realiza atividades profissionais na direção contrária aos objetivos que se propõe e, consequentemente, também na direção contrária aos interesses históricos da classe trabalhadora (VASCONCELOS, 2006, p. 3132).

Uma das explicações para esse distanciamento entre os referenciais teóricometodológicos e políticos com o espaço de exercício profissional é dada por Bravo e Matos (2007). Para eles, há uma lacuna teórica e política entre o Projeto da Reforma Sanitária, o projeto privatista e o surgimento dos Parâmetros para a Atuação de Assistentes Sociais na Política de Saúde. Pois o início dos anos 1990 foi uma época em que significou e deu-se início a uma tendência hegemônica na academia e nas entidades representativas da categoria profissional, com a intenção de ruptura do conservadorismo, abrindo espaço para a interlocução com a tradição marxista. Todavia, os profissionais que seguiam tal vertente se inseriram em sua maioria na academia, onde, dentro do processo de renovação do Serviço Social, pouco se efetivou na intervenção. Para que se consiga enxergar estas lacunas e superá-las, é necessário extrapolar os desafios que estão presentes no debate interno do Serviço Social e que continuamente vêm se tornando mais complexos por demandas conjunturais, a exemplo da avalanche de contrarreformas que o país vive desde 2016.

Nesse contexto, nos parece importante, em virtude do objetivo inicialmente exposto, identificar e problematizar o significado e os fundamentos dos Parâmetros para a Atuação de Assistentes Sociais na Política de Saúde, que foi elaborado entre os anos 2008 e 2009 e publicado em sua versão final no ano de 2010. Tal documento “[...] tem como finalidade referenciar a intervenção dos profissionais de Serviço Social na área da saúde" (CONSELHO FEDERAL DE SERVIÇO SOCIAL, 2010, p. 11). A construção dos Parâmetros foi coordenada pelo Grupo de Trabalho Serviço Social na Saúde do CFESS, o qual manuseou diversos documentos do Conselho Federal e dos Conselhos Regionais de Serviço Social, atividade de elaboração aliada a inúmeros debates descentralizados pelo país, à revisão da literatura e legislação. O resultado foi um documento que "[...] visa responder, portanto, a um histórico pleito da categoria em torno de orientações gerais sobre as respostas profissionais" (CONSELHO FEDERAL DE SERVIÇO SOCIAL, 2010, p. 11). Nesse sentido, ele traz uma análise sintética dos principais desafios que estão postos à profissão e ao Projeto de Reforma Sanitária, inclusive tratando de embates teóricos e das escolhas profissionais que vêm sendo realizadas pelos assistentes sociais.

Desde o seu lançamento, o documento dos Parâmetros para atuação de Assistentes Sociais na Política de Saúde vem sendo reconhecido no âmbito do serviço social, mas ainda genericamente, conforme apontam as seguintes autoras: "O documento vem explicitar as conexões entre o projeto ético-político da categoria com as bases da Reforma Sanitária e sugerir eixos para a prática do assistente social na saúde [...]" (KRÜGER, 2010, p. 129-130); “Torna-se indispensável ressaltar a importância dos 
Parâmetros para Atuação de Assistentes Sociais na Política de Saúde elaborados a partir de ampla participação da categoria profissional e promulgados pelo CFESS" (MARTINELLI, 2011, p. 500). E para Pereira (2013):

Este documento faz uma importante crítica e análise acerca da atuação dos assistentes sociais na saúde, revelando os vários desafios e possibilidades destes profissionais neste campo, que vem absorvendo uma parte significativa de assistentes sociais (PEREIRA, 2013, p. 160).

Os Parâmetros para atuação de Assistentes Sociais na Política de Saúde foram estruturados em três itens, sendo que os primeiros sustentam os quatro eixos norteadores de atuação em termos teóricos, políticos e metodológicos. O primeiro item - Saúde, Reforma Sanitária, Sistema Único de Saúde e desafios atuais - apresenta o tripé da Seguridade Social, com a perspectiva da garantia dos direitos sociais, atenção às reivindicações da classe trabalhadora, tendo o SUS como elemento fundamental e apontando os impasses vividos desde os anos 1990.

Já o segundo item, intitulado Serviço Social e Saúde, traz a discussão teórica e política presente no Serviço Social na Saúde. Neste item, é resgatada a trajetória do Serviço Social nessa política. Para os anos recentes, há a identificação de alguns desafios que os profissionais enfrentam nessa área, como a constatação de que ainda existem profissionais que, após realizarem uma formação em saúde pública, passam a não se reconhecerem mais como assistentes sociais e a tendência de denominar alguns trabalhos como serviço social clínico. Por fim, ressalta a importância de formar trabalhadores de saúde para o SUS, com visão generalista e não fragmentada, fazendo com que o assistente social seja um profissional que se articule com outros segmentos que defendam o SUS, efetivando o direito social à saúde.

No terceiro item, que fala sobre a Atuação do Assistente Social na Saúde, as atribuições e competências gerais do profissional são caracterizadas, enfatizando as ações deste na área da saúde, na perspectiva de permitir ao profissional realizar a análise crítica da realidade, utilizando como base o Código de Ética e a Lei de Regulamentação da profissão. Na continuidade, o subitem intitulado Parâmetros para a Atuação de Assistentes Sociais na Saúde explicita as principais ações desenvolvidas pelos profissionais que atuam na saúde, em quatro grandes eixos articulados entre si: a) atendimento direto aos usuários; b) mobilização, participação e controle social; c) investigação, planejamento e gestão; d) assessoria, qualificação e formação profissional. O texto afirma que as diversas ações estão interligadas e são complementares, apontando a uma equivalência no grau de importância entre as ações assistenciais, as de mobilização popular e as de pesquisa e planejamento do trabalho profissional. As possibilidades de trabalho a partir desses quatro eixos são indicadas por Krüger (2016):

Trabalhar a partir desses quatro eixos pressupõe retomar os fundamentos do SUS em sua perspectiva de projeto nacional para saúde de radicalidade democrática; considerar a articulação com os gestores, Conselhos de Políticas Púbicas, com assistentes sociais de outras instituições, com outros profissionais e movimentos sociais; não responder de forma psicologizante, 


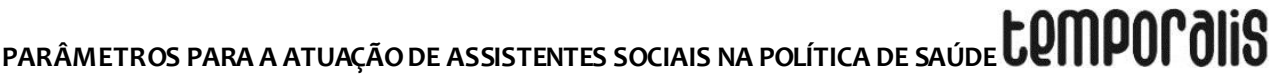

clínica e voluntarista; e potencializar as possibilidades de trabalho coletivo, com grupos e interdisciplinar (KRÜGER, 2016, p. 2).

Após apresentar os quatros eixos de atuação, vale atentar para as considerações do documento. O conjunto do texto (CFESS, 2010) “[...] procurou fazer uma análise sucinta da política de saúde, com ênfase nos principais desafios a ser em enfrentados na atualidade (CONSELHO FEDERAL DE SERVIÇO SOCIAL, 2010, p. 67)”, além de levantar questões consideradas polêmicas no espaço sociotécnico do trabalho, como, por exemplo, as atividades burocráticas que são demandadas diversas vezes aos assistentes sociais. Dessa forma, com os Parâmetros, há a intenção de trazer a reflexão relacionada aos diversos eixos da atuação profissional, na busca da garantia dos direitos sociais, do fortalecimento da participação social e da viabilização do SUS como uma tentativa de suprir uma lacuna que existe entre a atuação com o conservadorismo, o Projeto da Reforma Sanitária, o projeto privatista, o processo de renovação (Movimento de Reconceitualização) e os desafios sempre renovados pela conjuntura.

\section{Grupos focais: assistentes sociais da saúde}

Neste item, apresentamos os principais resultados sistematizados dos dados coletados junto aos sujeitos participantes dos grupos focais, procurando contribuir para o desocultamento da realidade do exercício profissional, processo fundamental para a coerente intervenção do assistente social em seu cotidiano de trabalho. Através de sua fala, cada sujeito contribuiu para esta produção teórica com suas experiências na política de saúde, mais especificamente nesse artigo, no âmbito hospitalar.

O roteiro semiestruturado foi utilizado para o debate nos grupos focais com questões referentes à identificação dos integrantes do grupo, aos desafios do exercício profissional no hospital e questões sobre os Parâmetros para a Atuação de Assistentes Sociais na Saúde (como utilizam o documento, caracterização das demandas atendidas de acordo com os quatro eixos de atuação do profissional na saúde e os aspectos destacados com relação ao Serviço Social na instituição em que atuam). No desenvolvimento desse texto, privilegiaremos algumas das questões sobre o reconhecimento do documento e os eixos norteadores do exercício profissional.

Para a coleta dos dados, foram realizados quatro grupos focais que aconteceram durante o mês de junho de 2017, agendados previamente, em salas privadas nas unidades hospitalares. As manifestações dos profissionais foram gravadas e posteriormente transcritas. Os grupos dividiram-se: dois de residentes e dois de trabalhadores das instituições. O primeiro grupo focal foi composto por cinco assistentes sociais residentes do HU/UFSC; o segundo composto por seis assistentes sociais residentes do $\mathrm{HU} \mathrm{UFSC}^{9}$; o terceiro realizado com cinco assistentes sociais de

\footnotetext{
${ }^{9}$ Dos onze residentes, quatro desses estavam no segundo ano de residência ( $R 2$ ) e sete no primeiro ano de residência (R1). Desses residentes oito possuem sua formação em serviço social pela Universidade Federal de Santa Catarina, nos anos de 2006, 2013, 2016 e 2017. Um residente formou-se na Universidade
}

Temporalis, Brasília (DF), ano 18, n. 35, jan./jun. 2018. 
um hospital geral da grande Florianópolis; o quarto e último grupo, realizado com três assistentes sociais do $\mathrm{HU}^{10}$. Dos 19 participantes dos grupos focais, 18 eram do sexo feminino e um do sexo masculino. Na apresentação dos dados, não diferenciaremos as falas dos profissionais e dos residentes, tratando igualmente todos como profissionais.

\title{
Parâmetros para a atuação de assistentes sociais na política de saúde e o exercício profissional
}

Inicialmente neste item, apresentaremos as falas dos profissionais que dizem respeito a como os Parâmetros para a Atuação de Assistentes Sociais na Saúde são utilizados e o significado dele no exercício profissional cotidiano.

\begin{abstract}
Os Parâmetros, eles têm norteado bastante a prática. Inclusive a gente faz assim, já fizemos reuniões estudando e vendo o que teria que estar melhorando e uma das coisas que se absorveu como atribuição do serviço social, que era o transporte. $E$ aí foi os Parâmetros que justificou essa prática que já foi ultrapassada e que já não era mais função do serviço social. $O$ documento indica como uma atividade técnico-administrativ[a]. E aí hoje quem está fazendo são os técnicos administrativos, mas com exceção da emergência que está ainda numa confusão, porque não tem técnicos suficientes para fazer (Sujeito 16).
\end{abstract}

A fala do sujeito 16 demonstra que o documento é reconhecido muitas vezes como um subsídio para que o profissional ou a equipe tenha embasamento para argumentar sobre o motivo de não realizar certas atividades, restringido o documento de subsídio a apenas essas situações. $O$ sujeito 7 reafirma em sua fala essa questão de olhar para 0 documento e entender o que é atribuição do assistente social e o que não é:

\begin{abstract}
Já li algumas vezes, mas, enfim, não sei de cor. Daí eu estava lendo aqui e identifiquei várias situações que colocam aqui que não deveria, que não é atribuição do assistente social e que o serviço de saúde vem requisitando, do assistente social e várias assim acontecem aqui no $\mathrm{HU}$, de forma bem comum (Sujeito 7).
\end{abstract}

Durante os grupos, foi possível perceber que cinco dos participantes mencionaram ter conhecido o documento na graduação e tiveram acesso apenas durante a graduação, conforme a fala do sujeito 4: "A minha aproximação com os Parâmetros vem da graduação, na disciplina referente à saúde" (Sujeito 4). Também pode ocorrer em situações pontuais, como estágios e até mesmo após estar formado, como destaca o sujeito 11: "Eu tomei contato com esse documento através de uma experiência que tive numa policlínica do interior [...] e até nem conhecia na época o documento" (Sujeito 11).

Federal de Mato Grosso, em 2015, um residente pela Universidade Federal de Santa Maria, no ano de 2015, e outro formado pela Universidade Estadual de Londrina, em 2016.

10 Dos grupos focais, participaram oito trabalhadores, cinco profissionais de um hospital da grande Florianópolis. Sete tiveram sua formação em serviço social pela Universidade Federal de Santa Catarina e um pela Unisul, nos anos de 1988, 1989, 1992, 2002, 2003, 2007 e 2009. O período que atuam na instituição varia entre dois anos e meio e vinte e dois anos. 


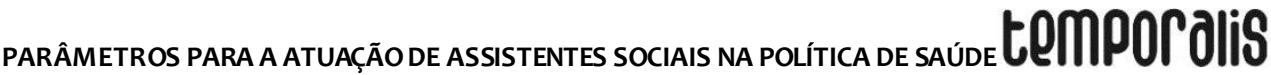

Das falas analisadas, alguns profissionais mencionaram conhecer pouco o documento, no sentido de reafirmarem a importância apenas para a parte dos Parâmetros que expõe os eixos. Contrapondo a fala da maioria dos residentes que mencionaram conhecer pouco o documento, o sujeito 8 afirma ter maior familiaridade: "Também conheci o documento através da aula. Depois também tive a oportunidade de ler quando eu era bolsista de iniciação científica PIBIC, onde se analisava o que é a ação profissional" (Sujeito 8).

O sujeito 4 afirma que teve a possibilidade, em alguns momentos teóricos da residência, de discutir sobre o documento, sem dar exemplos diferentes aos relacionados com as demandas e os respectivos eixos, "Nos nossos momentos de encontro específico, se faz discussão acerca desse documento, com as nossas tutoras, com as professoras, a gente discute" (Sujeito, 4).

Entretanto, mesmo os participantes mostrando pouco conhecimento do conteúdo do documento, algumas falas valorizam quando se trata da sua a importância, como vimos a seguir nos dizeres do sujeito 15: "Eu acho que ele veio para clarear mesmo a prática" (Sujeito 15). O sujeito 12 complementa afirmando que "[...] os Parâmetros realmente dão uma base, uma sustentação para o que a gente faz no dia a dia" (Sujeito 12). Por fim, o sujeito 5 traz também que "[...] ele serve sim como base, até porque o profissional tem que buscar o conhecimento além de ter ele pronto" (Sujeito 5). Do total de participantes da pesquisa, em torno de cinco profissionais afirmaram utilizar o documento em algumas situações do cotidiano profissional.

Por outro lado, alguns profissionais evidenciaram o significado do documento, como se explicita na fala seguinte:

Então, eu acho que por mais que o documento em si não sirva de base aqui para o serviço social do Hospital, a gente pode trazer ele durante nossa intervenção profissional. Esses eixos que têm dentro do documento, a gente acaba vendo na nossa intervenção profissional (Sujeito 5).

Outros profissionais destacaram que não é um documento utilizado no exercício profissional cotidiano, como afirma o sujeito 2: "Não é algo que a gente chega e é nos colocado quanto uma referência para atuação, algo que precise se aprofundar, ler e tudo mais. Não é algo que se tenha como referência principal” (Sujeito 2). O sujeito 1 concorda: "É, mas não é algo que a gente utiliza, tipo, olha estou com uma dúvida e eu vou me referenciar por esse documento, não, eu não acho que é isso" (Sujeito 1). Acrescentando às falas anteriores, o sujeito 19 afirma que há uma grande dificuldade de ele realmente se constituir em uma referência e avalia que não é competência do CFESS se manifestar quanto a esse conteúdo:

Eu nunca concordei que o CFESS tivesse que se manifestar em relação a construir um referencial, um bloco de referencial específico para a atuação, até porque ele não dá conta de uma dimensão muito heterogênea, porque vai diferenciar em cada espaço, em cada serviço, para cada profissional, para cada equipe. [...] mas não que tudo que eu faça ou se eu for sistematizar hoje algo da minha prática, ele não vai ser o documento que eu vou utilizar, não é,

Temporalis, Brasília (DF), ano 18, n. 35, jan./jun. 2018. 
talvez seja uma outra referência, de um outro autor com quem eu me identifique mais, mas ele não seria hoje um documento que eu escolheria para isso (Sujeito 19).

Em outro momento do grupo focal, este profissional parece repensar:

Como eu nunca estudei a fundo a demanda pela construção de Parâmetros que não ficou só na saúde, foi para outras áreas também, me parece que tenta dar um fôlego para a categoria em relação ao que se faz, dar nome aos processos, aos procedimentos. Eu acho que é um exercício, é válido, mas nem sempre espelha ou esclarece suficientemente sobre aquilo que se faz (Sujeito 19).

Para finalizar, trazemos mais uma fala que reafirma o que grande parte dos participantes trouxe: a não utilização dos Parâmetros no exercício profissional, conforme é explicitado pelo sujeito 17:

\begin{abstract}
Eu vou confessar, há muitos anos eu não leio os Parâmetros, de verdade. Ele, os Parâmetros, quando ele foi lançado, a gente fez uma discussão e inclusive fui a algumas reuniões. [...] é um documento que tem uma perspectiva de mobilização da categoria para pensar Parâmetros para assistência na saúde. E eu acho que isso é super válido, só que, no corpo do documento, me parece muito do que tu não pode fazer. Então, é uma realidade que o brasilzão afora, muito distinta... Não me identifiquei com algumas ações e indicadores ali que eles colocaram (Sujeito 17).
\end{abstract}

As falas acima evidenciaram que o documento é conhecido pelo nome, mas desconhecido em seu sentido técnico, teórico, político e metodológico pelos profissionais contemplados nesse estudo. A nosso ver, os participantes que disseram usar o documento como uma referência e os que não o reconhecem não conseguiram sustentar sua importância ou a falta dela. Não identificamos, nas falas dos profissionais, argumentos que ressaltem a importância de seu conteúdo ou mesmo questionando as bases do serviço social e do SUS que estruturam os Parâmetros.

Em outro momento do grupo focal, foi solicitado aos profissionais que caracterizassem as demandas no exercício profissional, conforme os eixos de atuação indicados nos Parâmetros: Eixo 1: Atendimento direto aos usuários (ações socioassistenciais; ações de articulação com a equipe de saúde e ações socioeducativas); Eixo 2: Ações de mobilização, participação e controle social; Eixo 3: Investigação, planejamento e gestão; Eixo 4: Assessoria, qualificação e formação profissional.

Na sua maioria, os profissionais apontaram que o exercício profissional nos hospitais se caracteriza essencialmente por centrar-se no Eixo 1 de Atendimento direto aos usuários, que se subdivide em ações socioassistenciais; ações de articulação com a equipe de saúde e ações socioeducativas. O relato a seguir do sujeito 11 é bastante ilustrativo:

Eu identifico que a gente mais atua, seria a de natureza assistencial e emergencial, é o que mais chega. Não que não se tenha outras dimensões, mas é o que somos mais chamados a responder no hospital. Mas acredito ainda e olhando para o documento e para os quatro eixos, ficamos muito 


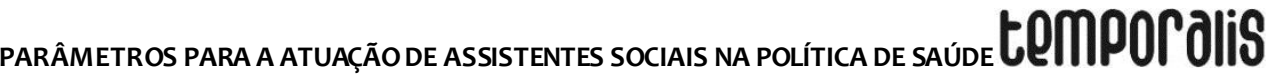

presos no atendimento direto aos usuários e numa dimensão de ações socioassistenciais, de articulação, às vezes, com a equipe; às vezes, com uma atividade socioeducativa (Sujeito 11).

Os profissionais participantes da pesquisa pertencem a dois grandes hospitais gerais que são referências no atendimento de demandas diversas de média e alta complexidade. Essas demandas em sua maioria surgem de forma espontânea (interna e externa), pois os usuários buscam por atendimento direto ou são encaminhados pelos mais diversos setores da unidade ao serviço social. Dada as inúmeras demandas espontâneas e encaminhadas ao serviço social, os profissionais mantêm em seu setor uma sala de plantão. Além de o plantão requerer muito tempo dos grupos de profissionais de cada unidade hospitalar, os vários serviços ambulatoriais e de internação colocam demandas para o serviço social que não se distanciam das demandas características do Eixo 1 - atendimento direto aos usuários.

A fala do sujeito 5 complementa a afirmação acima dizendo que é o " [...] assistencial e emergencial, que a gente acaba realizando aqui no hospital. Que por mais que sejam muitos profissionais, a rotina do hospital é assistencial e emergencial, então é aquele entendimento de saúde-doença" (Sujeito 5).

Validando tal afirmação, seguem as falas de outros participantes que possuem o mesmo olhar voltado para as demandas mais recorrentes no âmbito hospitalar. Vejamos, nesse sentido, o depoimento do sujeito 19: "Eu acho que, por exemplo, aqui, que a gente vai tomar esse primeiro tópico, demandas de natureza assistencial emergencial. Sim, esse é o nosso foco hoje" (Sujeito 19).

Eu acredito também que é assistencial-emergencial as demandas na maioria, mas conseguimos fazer a articulação com a equipe de saúde, a gente faz ações socioeducativas. O ambulatório de cirurgia bariátrica é um exemplo assim, é de ação socioeducativa (Sujeito 8).

O nosso trabalho fica nas demandas assistencial emergencial, só que a gente consegue trabalhar a articulação com a equipe de saúde e as ações socioeducativas, a gente trabalha nos grupos de pré-operatório, pósoperatório (Sujeito 16).

De acordo com os Parâmetros para a Atuação de Assistentes Sociais na Política de Saúde (CONSELHO FEDERAL DE SERVIÇO SOCIAL, 2010), as ações a serem desenvolvidas pelos profissionais devem ultrapassar o caráter emergencial e burocrático, bem como ter uma direção socioeducativa. Outra preocupação evidenciada no documento é que o atendimento do profissional não se torne psicoterapêutico aos pacientes e seus familiares, mas potencialize a ampliação do acesso dos indivíduos e da coletividade aos seus direitos. Com relação às falas anteriores, os participantes até chegam a mencionar as outras atividades desse mesmo eixo, mas dão ênfase ao atendimento direto aos usuários. Nas duas instituições, os profissionais afirmaram que conseguem articular com a equipe multiprofissional e também realizam ações socioeducativas, como é o caso dos ambulatórios, em que acontecem atendimentos junto à equipe multiprofissional e orientações realizadas a grupos e individualmente. 
Dadas as necessidades sociais e de saúde que no geral são imediatas, por se relacionarem com necessidades urgentes de alimentação, transporte, medicação, funeral, definição de diagnóstico, realização de exames, situações de violência, repouso, hospedagem, a resposta profissional não consegue escapar do assistencial e do emergencial. Seja pelo nome de plantão ou não, cabe aqui relacionar com uma reflexão de Vasconcelos (2009, p. 248):

O plantão é a única atividade comum à maioria dos assistentes sociais, ainda
que, em algumas unidades de saúde, esta atividade não seja reconhecida por
este nome. O plantão não se constitui assim, num serviço ou uma atividade
pensada, planejada, organizada, reduzindo-se a ações isoladas desenvolvidas
pelo assistente social para 'resolver o(s) problema(s) do usuário'
(VASCONCELOS, 2009, p. 248).

Sobre o Eixo 2, que compreende demandas relacionadas à mobilização, participação e controle social, poucas foram as manifestações nos grupos focais e destas ainda o que se evidenciou foi a não participação do serviço social nesses espaços. Desse modo, elencamos algumas falas a seguir. O sujeito 17 diz que a “[...] mobilização, participação e controle realmente a gente não consegue chegar lá, não faz" (Sujeito 17). Já o sujeito 7 afirma: "Essa questão mesmo da participação e o controle social e eu realmente não vejo isso acontecendo aqui na instituição, não sei se por ser um hospital, a ênfase [em] que nós estamos" (Sujeito 7).

Na questão da mobilização, participação e controle social, quando a colega falou dos grupos, eu lembrei um pouco do espaço do ambulatório de cirurgia bariátrica. Porque assim, nos aproximamos um pouco nos grupos junto com os pacientes e a gente sempre fala desses espaços. Não que façamos uma articulação direta, mas sempre se traz nos grupos sobre o controle social, incentivamos a participação nesses espaços, a gente incentiva que eles procurem no território aquilo que pode ser suporte no processo tratamento. E, na medida do possível, tentamos fazer articulação com esses espaços, mas acho que a gente faz pouco, mas está presente (Sujeito 4).

Eu acho que nessa parte também da mobilização, da participação e controle social, até que ponto também nós estamos participando, nós enquanto residente, enquanto profissional, estamos participando dessas conferências de saúde locais e não só da saúde porque ultrapassa. Perpassa não só a saúde, mas a assistência, a previdência, quanta gente está inserida nesses locais, no território mesmo, que nós vivemos e convivemos (Sujeito 5).

Nenhum dos profissionais e residentes tem envolvimento com os espaços de participação e, quando relacionam no exercício profissional, mencionam as orientações realizadas aos usuários para participarem de algum dos espaços de controle social. Isso nos faz refletir sobre o quanto, em nossos discursos da profissão e na literatura em geral, falamos de participação e o que na prática acaba acontecendo é bem o contrário: a nossa ausência enquanto categoria profissional, parecendo que delegamos isso como importante para os usuários.

No Eixo 3, sobre as ações de investigação, planejamento e gestão, há quase uma completa ausência de demandas levantadas durante as falas. Apenas conseguimos extrair das transcrições poucas manifestações sobre o eixo, que nos parecem bastante 


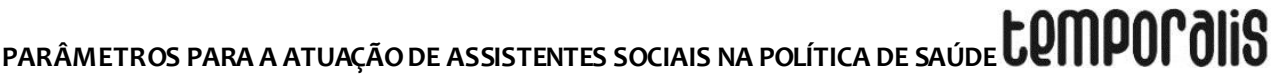

simplistas e restritas. No entanto, há que concordar com o profissional 17 quando ele diz que as demandas do cotidiano alimentam o processo de gestão de planejamento. No entanto, para esse profissional, o "Planejamento e gestão é a questão de tu discutir o que se faz o tempo todo e muito, pensar em fluxos, forma de atendimento, como é que tu vai receber isso e as milhões de reuniões que temos com a equipe e tudo mais" (Profissional 17). Dando continuidade, os sujeitos 2 e 15 relatam respectivamente que “[...] a gente estava pensando sobre o planejamento, gestão, mas acho que vai mais no sentido de projetos, de elaboração de projetos” (Sujeito 2 e Sujeito 5). O segundo deles assevera: "Ali, em relação ao planejamento, eu penso que é o planejamento que a gente faz quando inicia o ano, que a gente define algumas metas para trabalhar no decorrer do ano" (Sujeito 5).

O planejamento e gestão envolvem a contínua avaliação da política e dos serviços oferecidos, as bases de financiamento e sua direção ideopolítica numa correlação com as demandas do cotidiano dos serviços e indicadores socioeconômicos. Também podemos afirmar que estas falas dos sujeitos da pesquisa revelam um silêncio ou ausência da participação do serviço social em espaços de planejamento e gestão das políticas sociais e particularmente da saúde. E por conta do processo de descentralização das políticas sociais, o assistente social vem sendo cada vez mais requisitado para atuar nos níveis de planejamento, gestão e coordenação de equipes, programas e projetos. O assistente social atuante na gestão e planejamento busca a intersetorialidade dos serviços, objetivando contemplar a saúde no âmbito da seguridade social (CONSELHO FEDERAL DE SERVIÇO SOCIAL, 2010). E, para destacar a importância das ações desse eixo, recorremos ao texto de Bonin e Krüger (2015): "O instrumento chamado planejamento representa uma dimensão político-decisória na materialidade dos objetivos profissionais e das políticas sociais com as quais se trabalha" (BONIN; KRÜGER, 2015, p. 65). Além disso, planejar é uma das atribuições presentes na Lei de Regulamentação da Profissão ${ }^{11}$. Sendo assim, no exercício profissional do assistente social, a execução, o planejamento, a gestão e a formulação de políticas sociais são dimensões intrínsecas e complementares.

A quase completa ausência de atividades do serviço social que se relacionam a os eixos 2 e 3 sustenta e legitima as falas de que o foco do exercício profissional é o eixo das atividades diretas com o usuário. O local de trabalho dos profissionais são unidades de saúde que desenvolvem atividades de ensino e delas o serviço social faz parte, mas a dimensão da investigação que ao menos poderia se relacionar ao ensino não se explicitou. Entendemos que a explicação que Guerra (2009) dá ao ato de investigar e sua relação com os demais eixos da intervenção profissional merecem ser citadas:

\footnotetext{
${ }^{11}$ Elaborar, coordenar, executar e avaliar planos, programas e projetos que sejam do âmbito do Serviço Social com participação da sociedade civil. Planejar, organizar e administrar benefícios e Serviço Sociais. Planejar, executar e avaliar pesquisas que possam contribuir para a análise da realidade social e para subsidiar ações profissionais. Planejamento, organização e administração de Serviços Sociais e de Unidades de Serviço Social. Coordenar, elaborar, executar, supervisionar e avaliar estudos, pesquisas, planos, programas e projetos na área de Serviço Social; e Planejar, organizar e administrar programas e projetos em Unidades de Serviço Social (CONSELHO FEDERAL DE SERVIÇO SOCIAL, 2012): essas são competências e atribuições específicas dos assistentes sociais, necessárias ao enfrentamento das situações e demandas sociais que se apresentam no cotidiano profissional.
} 
A investigação é inerente à natureza de grande parte das competências profissionais: compreender o significado social da profissão e de seu desenvolvimento sócio-histórico, identificar as demandas presentes na sociedade, realizar pesquisas que subsidiem a formulação de políticas e ações profissionais, realizar visitas, perícias técnicas, laudos, informações e pareceres sobre matéria de Serviço Social, identificar recursos (GUERRA, 2009, p. 13).

Em relação ao Eixo 4, da assessoria, qualificação e formação profissional, foram destacadas algumas falas:

Pensando na residência, que não dá para deixar de falar enquanto um processo de qualificação e de formação profissional, de formação de uma maneira simultânea, conseguir atrelar teoria e prática, ao mesmo tempo, seus desafios e contradições (Sujeito 2).

E a assessoria, qualificação e formação profissional, é os estagiários que chegam, trazem um sangue novo, nós acabamos direcionando às vezes quando é possível, uma pesquisa, acaba ajudando o aluno a fazer um diagnóstico daquela determinada situação dentro do hospital, mas infelizmente, ficamos aqui no dia a dia, orientamos o estagiário, ele vem com uma bagagem teórica metodológica da universidade, conhecemos, sabemos do que se trata, mas a gente não para pra pensar, para refletir, para estudar, por conta do dia a dia, da demanda (Sujeito 12).

A qualificação e a formação profissional eu acho que até por conta da residência e do nosso campo, de ser um campo de estágio há muitos anos isso faz com que a gente a todo momento se organize, reflita e pensa nessa perspectiva. [...] essa questão da formação também e de como é rico essa troca, tanto com os residentes quanto com os estagiários, os estagiários também têm essa possibilidade. Não que os outros hospitais que não são universitários também não vão ter essa troca com os estagiários. Mas eu acho que o $\mathrm{HU}$, nós integramos um corpo de profissionais que está sempre envolvido com a academia (Sujeito 17).

Neste eixo, através das falas de alguns participantes, é possível destacar que, com relação às atividades de formação profissional, a supervisão de estágio é uma das atribuições do profissional desenvolvida nas duas instituições. O vínculo com as atividades da residência e estagiários é elencado como uma espécie de formação permanente dos profissionais e a qualificação, subsídio primordial para que os profissionais se mantenham atualizados.

A assessoria como uma das dimensões do eixo 4 pode ser realizada a profissionais, instituições, à gestão, grupos temáticos e a movimentos sociais. Quanto à assessoria, durante os grupos, houve silêncio e falta de qualquer comentário em relação, até porque pode não parecer para os profissionais que seja uma atividade que se realiza no âmbito da instituição hospitalar.

Ao final do grupo focal, indagamos os profissionais sobre quais as principais referências teóricas, políticas, operacionais e legais que buscam no exercício profissional na política de saúde. As referências mais citadas utilizadas como subsídio ao exercício profissional foram legislações: LOAS, LOS, Leis n 8080/1990 e 814/19902, 


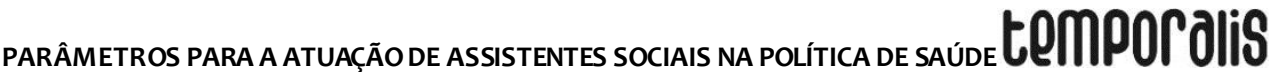

Código de Ética, documentos políticos, alguns autores como Marilda Villela Iamamoto, Maria Inês Souza Bravo e Ana Maria de Vasconcelos. Quanto à referência operacional, por diversas vezes nos grupos, os participantes do Hospital Universitário citaram o Procedimento Operacional Padrão (POP), mas a grande maioria dos residentes não sabia informar de que forma ocorreu seu processo de construção, quais referen ciais foram utilizados, qual é a última versão.

A seguir, duas falas representativas dos principais referenciais:

As nossas referências são Código de Ética, Estatuto do Idoso, Estatuto da Criança e do Adolescente, LOAS, tudo que se refere ao andamento da nossa prática. O que mais? Os Parâmetros para Atuação do Assistente Social na Saúde, um documento novo e que a gente percebe que é um documento que está muito dentro da nossa prática. A própria Lei do SUS (Sujeito 15).

A fala do sujeito 15 é uma fala bastante representativa, pois o Código de Ética, Lei de Regulamentação da Profissão, ECA, Estatuto do Idoso, LOS e LOAS foram as referências mais citadas nos grupos. Alguns participantes citaram autores amplamente conhecidos na literatura profissional. As legislações e políticas setoriais (população e situação de rua, método canguru...) são, a nosso ver, elementos de base técnica e política para que se consiga responder institucionalmente às demandas dos diferentes segmentos sociais, gênero, etnia, geracional, portadores de patologia, pessoas com deficiência, direitos previdenciários, trabalhistas, entre outros.

\footnotetext{
Os Parâmetros perpassam o projeto ético-político, a Lei de Regulamentação da Profissão. Ele contém uma série de referenciais teóricos. Então, por exemplo, as legislações que a gente tem que se embasar para fazer o exercício profissional, por exemplo, da rede de urgência e emergência, eu vou ter que lá olhar as portarias, as legislações. Não tem como atuar sem conhecer todas as legislações, as orientações, normas técnicas, por exemplo, a política de humanização. Enfim, a lei que determina como é que deve ser o critério de classificação de risco na urgência e emergência, o acolhimento (Sujeito 11).
}

Nesta fala, o que o profissional chama de referência teórica é o conjunto de legislações e políticas setoriais, o que coincide com a fala anterior. Em nosso entendimento, a legislação e as políticas setoriais são as referências de base técnico-operacional, institucional e de horizonte político. Os Parâmetros com certeza representam um marco político e técnico para o exercício profissional do serviço social na saúde, mas ele não reduz a isso, vai além, pois seus fundamentos estão colados ao projeto ético e político da profissão e do SUS. Portanto, é um documento que representa uma direção social progressista para a profissão.

No conjunto dos dados da pesquisa aqui apresentada, evidenciamos o caráter contraditório do exercício profissional no processo de reprodução das relações sociais e na dinâmica do cotidiano nas instituições. Mas o exercício profissional na área da saúde e a utilização ou não dos Parâmetros como referência devem ser colocados em um contexto de análise da profissão, com sua história, demandas, tarefas e 
atribuições. Procuramos fazer este exercício ao longo das partes iniciais desse texto. Como afirma Yazbek (2016), não há momentos históricos que sejam homogêneos, não há espaços sem contradição, assim como não há para o serviço social neutralidade ou possibilidade de deixar de participar desse processo, cuja direção está sempre em disputa.

Assim, apreender o exercício profissional na saúde, por meio do significado que o documento dos Parâmetros representa, consiste considerar o contexto de disputas do SUS nos últimos 30 anos, nos quais os acenos progressistas foram muito tímidos. Portanto, o serviço social, dada a sua histórica predominância de práticas com o assistencial e o emergencial, a conjuntura de disputas regressiva em que as demandas para o profissional chegam mais empobrecidas, doentes e ou vitimadas pelas diferentes violências, com serviços públicos desestruturados, restritivos e desfinanciados, acaba tomando muito de seu tempo de trabalho mesmo para prestar a mínima assistência ou realizar um simples encaminhamento.

E dentre os desafios que a profissão enfrenta para dar materialidade aos princípios de seu projeto ético-político, recorremos a Vasconcelos (2006):

\footnotetext{
Um dos grandes desafios enfrentados pelos assistentes sociais é trabalhar demandas, pleitos, exigências imediatas - a dor, o sofrimento, falta de tudo, a eminência da morte, da perda do outro, a falta de condições de trabalho, as condições de vida - sem perder a perspectiva de médio e longo prazo (VASCONCELOS, 2006, p. 21).
}

Compreendemos que os Parâmetros para a Atuação de Assistentes Sociais na Política de Saúde se situam nessas disputas acima sinalizadas no âmbito do SUS e que os profissionais também envolvidos nas disputas da reprodução das relações sociais se deparam com as demandas imediatas de sobrevivência da classe trabalhadora. Desse modo, talvez possamos explicar a ênfase assinalada pelos integrantes dos grupos focais que o cotidiano do serviço social nos hospitais é majoritariamente pautado no atendimento direto (assistencial e emergencial). Mas essa justificativa não nos faz perder de vista que o exercício profissional, por mais pressionado que seja pelas necessidades do cotidiano, não pode perder a perspectiva de médio e longo prazo. Isso faz compreender que os outros 3 eixos da dimensão do exercício profissional situam-se numa perspectiva de trabalhar com horizonte de médio e longo prazo. As demandas individuais situam-se num campo de necessidades sociais e de saúde que são públicas e coletivas. Mas compreender a demanda como de interesse público e coletivo não está no âmbito da aparência, do emergencial, do individual e do imediato, posto que exige do serviço social um esforço de mediações histórico-sociais, teóricas, metodológicas, técnicas e políticas. E aí o esforço não é apenas individual do profissional, mas exigência do conjunto da categoria por meio das unidades de ensino e dos órgãos representativos.

\section{CONSIDERAÇÕES FINAIS}

Os resultados desta pesquisa apontam para uma realidade de que os Parâmetros para a Atuação de Assistentes Sociais na Política de Saúde são bastante desconhecidos 


\section{Berainer ros}

pelos profissionais e referenciam pouco o exercício profissional na saúde. Os grupos focais representaram um processo pedagógico no qual as falas entre os profissionais participantes levaram a reflexões sobre o exercício profissional no âmbito hospitalar, permitindo afirmar que o documento dos Parâmetros não é utilizado no cotidiano profissional. Muitos dos sujeitos afirmaram que tiveram o primeiro contato com o referido documento durante a graduação - pois parte dos integrantes vem de uma geração que se formou após a sua publicação - ou em algumas situações específicas, não perpassando o cotidiano desses profissionais.

Referente à estruturação dos Parâmetros para a Atuação de Assistentes Sociais na Política de Saúde com a primeira parte pertinente aos fundamentos, não foi algo que apareceu durante os debates. Apenas sobre os quatro grandes eixos de atuação foram levantadas algumas situações, relacionando os eixos com as demandas mais recorrentes ao serviço social, sendo as demandas de natureza assistencial/emergencial as mais citadas.

O exercício profissional dos assistentes sociais participantes da pesquisa, diante dos Parâmetros para a Atuação de Assistentes Sociais na Política de Saúde, na sua maioria, aponta para uma atividade muito vinculada ao que é ou não é atribuição do assistente social. Houve dificuldades em conseguir fazer mediações do exercício profissional cotidiano aos fundamentos do SUS, do Projeto da Reforma Sanitária, o projeto éticopolítico e a conjuntura regressiva de ampla restrição dos direitos sociais e empobrecimento severo da classe trabalhadora, evidenciando quase uma relação administrativa com o documento. Entretanto, é importante compreender que o profissional não deve restringir sua atuação apenas às demandas emergentes, tornando seu trabalho focalizado: é necessário que o serviço social, com mediações estruturais e conjunturais, ultrapasse o que lhe é posto institucionalmente e o que lhe é posto pelas relações sociais.

O documento, como já reportado, faz uma importante crítica e análise em relação à atuação dos assistentes sociais na saúde e revela vários desafios e possibilidades destes profissionais neste campo, uma área de atuação que vem abarcando uma parte significativa de assistentes sociais. É um documento que tem referências e fundamentos de ordem teórica, política e técnica, fazendo parte da constituição política da profissão num contexto de contrarreforma do Estado e dos direitos sociais, com as particularidades do SUS.

Entende-se que os Parâmetros para a Atuação de Assistentes Sociais na Política de Saúde, por já possuírem quase uma década de vida, foram construídos em um cenário que passou por mudanças. Sendo assim, ele é um instrumento de base democráticopopular, que entendemos não ser o único para subsidiar o exercício profissional, pois não há um protocolo ou algo do tipo que vá (e nem defendemos algo do gênero) mostrar como o profissional deve atuar em cada demanda que se apresenta. No entanto, avaliamos como relevante que a categoria realize avaliações e pesquisas quanto ao referido documento, apontando seus limites, possibilidades e este que seja tornado público. 
Por fim, os Parâmetros para a Atuação de Assistentes Sociais na Política de Saúde possuem o mérito de se estruturar com base nos fundamentos do SUS e dos princípios do projeto ético-político do serviço social e por ter emergido de órgãos representativos da categoria (conjunto CFESS/CRESS). Mas não desconhecemos - e as respostas dos participantes da pesquisa comprovam - que sua primeira década de vida, sua forma de organização, seu referencial político e sugestões de eixo de atuação estão em meio a disputas no âmbito da categoria.

\section{REFERÊNCIAS}

AROUCA, Antônio Sérgio da Silva. Saúde e democracia. In: CONFERÊNCIA NACIONAL DE SAÚDE, 8., 1986, Brasília (DF). Anais... Brasilia (DF): Centro de Documentação do Ministério da Saúde, 1987.

BEHRING, Elaine R. Brasil em contra-reforma: desestruturação do Estado e perda de direitos. São Paulo: Cortez, 2008.

BONIN, Silvana; KRÜGER, Tânia Regina. Planejamento e Serviço Social. Sociedade em Debate, Pelotas, v. 21, n. 2, p. 63-83, 2015.

BRAVO, Maria Inês Souza. Saúde e Serviço Social no século XX. In: BRAVO, Maria Inês Souza. Saúde e Serviço Social no capitalismo: fundamentos sócio-históricos. São Paulo: Cortez, 2013.

BRAVO, Maria Inês Souza; MATOS, Maurílio Castro. O projeto ético-político do Serviço Social e sua relação com a Reforma Sanitária: Elementos para o Debate. In: MOTA, A. E. et al. (Org.). Serviço Social e saúde: formação e trabalho profissional. 2. ed. São Paulo: Cortez, 2007.p. 199-215.

BRAVO, M. I. S. PELAEZ, E. J.; PINHEIRO, W. N. As contrarreformas na política de saúde do governo Temer. Argumentum, Vitória, v. 10, n.1, p. 9-23, jan./abr. 2018.

CONSELHO FEDERAL DE SERVIÇO SOCIAL. Código de Ética Profissional do Assistente Social. 10. ed. Brasília (DF), 2012.

CONSELHO FEDERAL DE SERVIÇO SOCIAL. Parâmetros para atuação de Assistentes Sociais na política de saúde. Brasília (DF), 2010. (Série: Trabalho e projeto profissional nas políticas sociais).

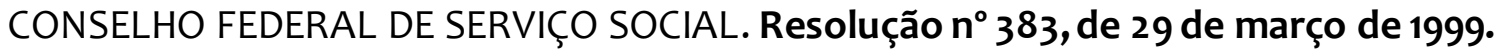
Caracteriza o assistente social como profissional da saúde. Brasília (DF), 1999.

CONSELHO FEDERAL DE SERVIÇO SOCIAL. Código de Ética do/a Assistente Social: Lei 8.662/93 de regulamentação da profissão. Brasilia (DF), 1993.

CONSELHO NACIONAL DE SAÚDE. Resolução n²18, de 06 de março de 1997. Brasília (DF), 1997. 


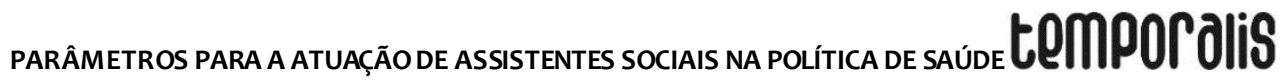

GONDIN, S. M. G. Grupos focais como técnica de investigação qualitativa: desafios metodológicos. Paidéia, Ribeirão Preto, v. 24, n. 12, p. 149-161, 2003.

GUERRA, Yolanda. A dimensão investigativa no exercício profissional. In: SERVIÇO Social: direitos sociais e competências profissionais. Rio de Janeiro, 2009.

KRÜGER, Tânia Regina. Serviço Social e SUS: Conjuntura Regressiva e Exercício Profissional. Boletim Eletrônico, Florianopólis: Conselho Regional de Serviço Social Região $12^{\mathrm{a}}$ - Santa Catarina, n. 44, out. 2016.

KRÜGER, Tânia Regina. Serviço Social e Saúde: espaços de atuação a partir do SUS. Serviço Social \& Saúde, Campinas, v. 9, n. 10, dez. 2010.

MACHADO, Angelita Gnecco. A percepção dos usuários do plantão social acerca da atuação do serviço social. 2008. 94f. Trabalho de Conclusão de Curso (Curso de Serviço Social)- Centro Socioeconômico, Universidade Federal de Santa Catarina, Florianópolis, 2008.

MACHADO, Cristiane Ferrari Canez. Os assistentes sociais nos conselhos de assistência social como representantes do gestor. 2015. 203 p. Dissertação (Mestrado em Serviço Social)- Programa de Pós-Graduação em Serviço Social do Centro Socioeconômico da Universidade Federal de Santa Catarina, Florianópolis, 2015.

MARTINELLI, Maria Lúcia. O trabalho do assistente social em contextos hospitalares: desafios cotidianos. Ser. Soc. Soc., São Paulo, n. 107, p. 497-508, jul./set. 2011.

PEREIRA, Raffaelle Pedroso. O projeto profissional crítico e a intervenção dos assistentes sociais nos hospitais gerais do município de Juiz de Fora (MG). Dissertação (Mestrado em Serviço Social)-Programa de Pós-Graduação em Serviço Social da Universidade Federal de Juiz de Fora, Juiz de Fora, 2013.

SÓ FILOSOFIA (Brasil). Dicionário de Filosofia. Verbete: significado. Porto Alegre, C2008-2018. Disponível em: <http://www. filosofia.com.br/dicionario.php>. Acesso em: 10 jan. 2018.

SOARES, Raquel Cavalcante. A contrarreforma na política de saúde e o SUS hoje: impactos e demandas ao serviço social. 2010, 209f. Tese (Doutorado de Serviço Social)Programa de Pós-Graduação em Serviço Social do Curso de Serviço Social da Universidade Federal de Pernambuco, Recife, 2010. Disponível em: <http://pct.capes.gov.br/teses/2010/25001019031P3/TES.PDF >. Acesso em: 28 maio 2018.

TRAD, L. A. B. Grupos focais: conceitos, procedimentos e reflexões baseadas em experiências com o uso da técnica em pesquisa de saúde. Physis - Revista de Saúde Coletiva, Rio de Janeiro, v. 19, n. 3, p. 777-796, 2009. 


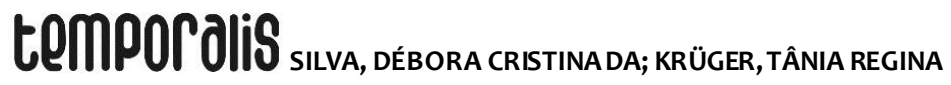

VASCONCELOS, Ana Maria. A prática do Serviço Social: cotidiano, formação e alternativas na área da saúde. 3. ed. São Paulo: Cortez, 2006.

VIEIRA, F. S.; BENEVIDES, R. S. O direito à saúde no Brasil em tempos de crise econômica, ajuste fiscal e reforma implícita do Estado. Revista de Estudos e Pesquisas sobre as Américas, Brasília (DF), v. 10, n. 3, p. 1-28, 2016 a.

VIEIRA, F. S.; BENEVIDES, R. S. Os impactos do Novo Regime Fiscal para o financiamento do Sistema Único de Saúde e para a efetivação do direito à saúde no Brasil. Brasília (DF): Ipea, 2016b. (Nota Técnica, n. 28).

YASBEK, Maria Carmelita. Prefácio: Serviço Social no Brasil... In. SILVA, M. L. O. (Org.) Serviço Social no Brasil: histórico de resistências e de rupturas com o conservadorismo. São Paulo: Cortez, 2016. p. 25-48. 